\title{
Visions of Illness, Disease, and Sickness in Mobile Health Applications
}

\author{
Margaret Machniak Sommervold * (D) and Maja van der Velden \\ Department of Informatics, University of Oslo, Problemveien 7, 0315 Oslo, Norway; majava@ifi.uio.no \\ * Correspondence: margarma@ifi.uio.no; Tel.: +47-404-69-782
}

Received: 18 June 2017; Accepted: 23 October 2017; Published: 26 October 2017

\begin{abstract}
Popular media and public health care discourses describe an increasing number of mobile health technologies. These applications tend to be presented as a means of achieving patient empowerment, patient-centered care, and cost-reduction in public health care. Few of these accounts examine the health perspectives informing these technologies or the practices of the users of mobile health applications and the kind of data they collect. This article proposes a critical approach to analyzing digital health technologies based on different visions of disease, namely disease, illness, and sickness. The proposed analytical classification system is applied to a set of "mobile health solutions" presented by the Norwegian Technology Council and juxtaposed with the reported use and non-use of several mobile health applications among young patients with Inflammatory Bowel Disease (IBD). The discussion shows how visions on health and disease can affect a patient's embodied experiences of a physical condition, and, secondly, illustrates how the particular vision inscribed in a mobile health technology can be negotiated to include the patient's vision.
\end{abstract}

Keywords: empowerment; vision; mediation

\section{Introduction}

In the past couple of decades, health care sectors worldwide have experienced an increasing number of demands for more advanced treatment and care, earlier discovery of diseases and chronic conditions, and the treatment of a growing number of patients [1]. At the same time, self-care and patient empowerment have emerged as important phenomena in the context of health and disease management and for supporting the work of health care providers. Within these two related concepts, the patients become active participants who engage in self-care through assuming a central role in the "action-taking" in their health and health care [2]. Coupled with the advancements in and the spread of digital technologies, digital health technologies [3] are being designed and developed in the hope of providing better care [4]. Mobile health technologies are argued to "translate everyday processes into information" [5] (p. 80), including physical activity and bodily dys/functions. Because of people's tendency to carry their mobile phones everywhere and close to their bodies [6], mobile health applications offer new and interesting possibilities for health promotion [3], self-diagnosing [7], as well as promoting patient empowerment and reducing health care costs $[3,8]$. These technologies have caught the attention of health care sector policymakers, politicians, and the media, who tend to present digital health technologies in largely uncritical ways [9]. In Norway, this discourse portrays mobile health applications as sources of empowerment, health management, and a more efficient and patient-centered health care [10], without demonstrating the actual use of these technologies by patients.

In August 2016, the Norwegian Technology Council (Teknologirådet; NTC), which serves as an independent advisory board to the Norwegian government, contributed to this discourse on mobile health applications by publishing a list of the so-called "Mobile Health Solutions" [11]. This list was part of their ongoing "Mobile Health" project. The intention was to give an overview of 
existing mobile health applications that can perform health measurements and self-tests, as well as to provide information on whether these solutions were approved by the American Food and Drug Administration or are provided with the CE mark, meaning that they adhere to current EU regulations. In a supplementary leaflet, the NTC discusses medical diagnostics as expensive and dependent on laboratories, hospitals, and medical offices. An alternative to these costly examinations are mobile self-tests that can be purchased without health care services functioning as an intermediary, which, according to the NTC, may relieve the health care system of expenditures and contribute to the earlier discovery of diseases. In other words, the technologies were presented in a medical as well as economic discourse.

The NTC's list of mobile health solutions has inspired several newspaper articles in Norway and, as a result of the NTC's status as a national advisory board, this list is used in governmental policy-making. Recent governmental proposals present the new health technologies as what Lupton [9] refers to as "magic bullets", by stating that "new technologies give better possibilities of mastering one's own life and health" (translated from Norwegian, [12]). The Norwegian media also frequently refer to mobile health applications as "solutions" [8] and thus confirm Lupton's [9] observation of largely uncritical accounts by the popular media and in public health publications.

There is a growing critical discourse surrounding digital health technologies, which argues that simple accounts, such as the "Mobile Health Solutions" list presented by the NTC, strengthen the ongoing processes of increased surveillance and digitalization of health care. Furthermore, such accounts may support technological and social divides, thus promoting specific political agendas that are increasingly persuading patients into tracking and monitoring the body [13,14]. According to Hofmann [4], digital health technology alters the responsibility of humans and institutions. This shift in the locus of responsibility can be explained as part of the patient-centered health care movement and empowerment of patients. In a more critical perspective, this shift can be understood as efforts to promote a form of citizenship in which citizen behave productively and in the interest of the state by voluntarily engaging in self-surveillance to improve their health and reduce health care expenditure [15].

The differences in understanding digital health technologies, between actors such as the NTC and actors in the field of critical research, can be understood in terms of different visions of the potential of technology and, more importantly, what constitutes a disease and what is a meaningful way to track a body. The NTC's account contains several visions: the cost vision, which presents disease as a governmental and social cost and technology can mediate a cost-reduction; the commercial vision, which sees profit opportunities for Norwegian tech companies; and the medical vision, which presents self-tracking as an opportunity for bettering research and treatment of diseases. These visions also contribute to the creation of technology needs and design requirements that further reinforce the dominant discourse on digital health technologies. The "Mobile Health Solutions" list is a product of the vision and interests of the NTC. Although the technologies on the NTC list have not been developed or designed by the NTC, the list mediates visions and epistemologies of what it means to track the body, what constitutes a disease, and how a disease is enacted.

Technology establishes how we act toward a disease by contributing to the discovery, diagnosis, and treatment of diseases [16], but tends to "tell partial stories of much larger lives" [5] (p. 80), meaning that the data collected by the technology might not take into the account the fluid lines dividing health and disease in a patient's life. Feeding this information back to the users constitutes moral actions and may have implications for the proclaimed empowerment of patients, who have an embodied and often conflicting vision of their body and disease. In this paper, we will focus on visions of health and disease mediated by technologies and ask: how can patients negotiate the visions mediated by mobile health technologies to become more empowered knowers of their body? 


\section{Aim of the Article}

In this article, we will focus on the tension resulting from the different visions mediated, inscribed in, re-produced, and promoted by digital health technologies. We understand visions as generative, often future-oriented, constructs that inspire, shape, and mobilize a wide variety of activities, such as technology design, research, discourses, funding, policy, and perceptions. With our particular focus, we aim to contribute to the growing body of critical inquiries into digital health technologies by proposing an analytical classification system drawn from social studies and medical philosophy, which is based on three perspectives on disease, namely disease, illness, and sickness. The three perspectives represent often contested but interlinked visions and epistemologies or ways of knowing in health care policy and practice, including the issue of who can be a knower in health care. Patient empowerment and patient-centered health care envision a role for the patient as an active participant, which entails the role of a knower in his or her health and care.

Exploring the visions shaping the design, promotion, and use of mobile health applications enables us to understand how patients negotiate these visions. We do this by applying our classification system to two data sets. The first set consists of the NTC's list of "Mobile Health Solutions". This dataset represents the vision of the NTC as well as the visions of the design and development team of each of the technologies on the list. The second dataset consists of empirical material on the use of mobile health applications. This data is extracted from interviews with 15 young patients diagnosed with Inflammatory Bowel Disease (IBD). The patients took part in a larger project on the transition from child-centered to adult-oriented health care services. We present the two sets of data to draw attention to the disconnections between the various visions.

The remainder of this paper is structured as follows: Firstly, we will present the background concepts and literature that have informed the research approach of this article. In this section, we will focus on the concept of vision and the three perspectives central to our analysis-disease, illness, and sickness. In Section 3, we will explain our research approach - the classification system, and the datasets. Our data includes testimonies on the use of mobile health applications by young patients, highlighting the ways in which patients use and appropriate various applications. We have split our analysis and discussion into two separate sections. Section 4 presents the analysis and discussion of the overall functionality of the analyzed mobile health applications based on the list by the NTC and the applications reported by the young patients. Section 5 presents an analysis and discussion based on the use and appropriation of mobile health applications by the young patients, followed by a discussion on patient empowerment and the design of mobile health technologies. Lastly, we describe our suggestions for future work on the design of mobile health applications and present our concluding remarks in Section 6.

\section{Background}

Central to mobile health applications is the tracking of bodily functions and physical activity, commonly referred to as self-tracking or quantified self. Self-tracking activities are linked to the empowerment of patients through the promise of offering new knowledge about the body, which might lead to new practices, bodily changes, and better health outcomes $[3,14,17,18]$. In the context of institutionalized health care, knowledge of the body and the disease has always been fundamental to diagnosis, treatment, and care. To prescribe the appropriate treatment or care, a disease must be localized and quantified [19]. Inherent in the individual meetings between patients and health care institutions, or the process of diagnosing taking place between a doctor or a patient, is the distinction between knowing subjects, the medical practitioners, and objects known, the patients [19]. Mol [19] (p. 27) describes this meeting as an enactment of the medical gaze: "[w]hen doctor and patient act together in the consultation room, they jointly give shape to the reality of the patient's hurting legs". This enactment is by no means homogeneous, as this enactment depends on, and is entwined with, various technologies to "render the body more visible" $[10,19,20]$. Due to the entwinement of medical practice with medical technology, e.g., stethoscopes or x-ray machines, medicine can be understood 
as technoscience [21,22]. Medical technologies extend the practitioner's vision beyond the skin of the patient to quantify and to allow for the localization of pathologies. This technoscientific process, performed by the medical practitioners, is negotiated with the patients and their experiences, and results in knowledge of the patient's body that can be treated and cared for with current medical and pharmaceutical knowledge.

Due to the diffusion of digital health technologies, the medical gaze is now re-negotiated, explored, and shared by other actors, and makes aspects of the patients' lives that were, until now, out of reach of the health care institutions, accessible to them [18]. As a result, both health care professionals and patients participate in producing descriptions of the body that can be redistributed, technologized, and capitalized [9]. The data doubles, the digital data collected about the individual and portraying her in a certain way [5,23], unfold in the relationship between users and their technologies and add value to aspects of the body and to activities that before were deemed without value [14].

Much like the medical instruments, self-tracking and self-measurement technologies are perceived as offering insights that are objective and factual, rather than embodied and situated [13,15]. Perhaps this reflects the dominant understanding of science among the general population in Western societies, which is based on "disembodied scientific objectivity", which Donna Haraway describes as "visions from nowhere" [21]. Haraway [24] argues that a vision is always from somewhere; it is situated in epistemologies, knowledge, policies, practices, and discourses. A vision also requires instruments of vision [21]. Thus, digital health technologies mediate the vision of medical practitioners as well as the situated visions of people who designed the technology.

One needs to proceed cautiously within the terminology of vision and mediation to not confuse technologies with tools to visualize or to extend our bodies. Verbeek [25] (p. 393) explains that "human beings and their world are products of mediation, not a starting point". Although technologies can be understood as tools for "recrafting our bodies", they should also be seen as means to enforce meanings [24] (p. 164). It is the designers who translate "the world into a problem of coding" [24] and inscribe a specific vision of the world in new technological artifacts [26]. Consequently, whose vision is inscribed into digital health technologies becomes a question of who can be a knower of a body and how this knowledge can be obtained.

Can one be both an object known and a knowing subject within the technology-mediated visions of health and disease? We looked for a place to start addressing this question in the writings of Annemarie Mol and Donna Haraway. Mol [19] introduced the concept of enactment of the medical gaze, which enables the understanding that the medical gaze is as much a situated vision as the vision of the patient. The patient and the doctor can be understood as having their particular visions, epistemologies, and interests and enacted them in their meetings. This coalition between Mol's enactment and Haraway's situated visions allows us to illuminate the various visions and assumptions about patient empowerment: who can be the knower of a body that is mediated in and through technologies.

\section{Visions of Disease}

There are varying visions on disease, and this has significant implications, not only for medical science and practice, but also for the way in which we structure our societies, what research we fund, and who can be called a patient. Because the productivity of societies is argued to be structured around health and disease, what constitutes a disease is highly political. Among others, Mol [19] explains how medical practitioners contribute to the maintenance of the social order in modern societies. If a person is ill, she must seek medical assistance. The doctor then either sanctions the patient's behavior or "sends [her] back to work" [19] (p. 57) and hence exert social control. Yet, the precise definition of the concept of disease is lacking and has been the subject of discussion in medical philosophy.

In a discussion of the slipperiness of the disease concept, Hofmann [27] explains that there are three relating and overlapping perspectives for analyzing disease: illness, disease, and sickness (Figure 1). The terms are defined by Hofmann [27] as follows: Illness, or "being sick", is a term meant to describe the (negative and) subjective experience characterized by pain, suffering, symptoms, and syndromes. 
Disease, or "having a disease", implies findings and classifications executed by medical professionals and is characterized by signs and markers. Sickness, or the "sick role", refers to being perceived as sick in the social context and is characterized by social behavior. The sick role has been discussed extensively in the context of functionalist theory, e.g., [28,29], and in terms of the implications for the patient-doctor relationship [19,30].

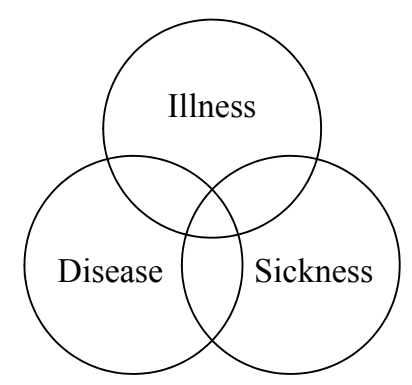

Figure 1. The model of the relationship between the different perspectives [27].

Although the three perspectives differ epistemologically and each has its knowers and ways of knowing the body and its disease, the perspectives are related and dependent on each other. Räikkä [31] argues that "[a]lthough the medical concept and the social concept may be closely related in many ways, neither is reducible to the other. The fact that a condition qualifies as a disease in the medical sense does not by itself entail that it qualifies as a disease in the social sense, or vice-versa" [31] (p. 359). Nevertheless, each perspective is favored by the group whose practice and understanding they represent and support. Health care professionals favor the disease perspective as it is most instrumental to them and is grounded in their discipline, epistemology, and practice. In Foucault's words, knowledge of disease is "the doctor's compass" [20], and the signs and markers that constitute this perspective allow for correct diagnosis and administration of treatment. The illness perspective positions patients as the knowers of their pain and suffering, but is also gaining importance in health care due to its link to well-being $[32,33]$. The renegotiation of the illness and disease perspectives in patient-doctor relationships aims toward the legitimization of the sickness of the patients, which may be important for the patient's identity. The importance of sickness for the identity of patients has been explored, by among others Pols [34], in a study of people with Chronic Obstructive Pulmonary Disease (COPD). Pols showed that patients needed a form of presence or visibility of their disease to create a social position within which they could have productive lives. In the study, the technologies aiding the patients, mobility scooters, helped to make the patient's invisible disease visible to others and validated their sickness role.

\section{Research Approach}

Our focus on visions and the enactment of these visions guided our research approach. To elucidate the various visions inscribed in and mediated by mobile health applications, we developed a classification system based on Hofmann's three perspectives, disease, illness, and sickness [27], to visualize with which of these visions the various mobile health applications were affiliated (Table 1). According to Bowker and Star [35] (p. 10), a classification system "is a set of boxes (metaphorical or literal) into which things can be put to some kind of work-bureaucratic or knowledge production". Our system is based on our analytical framework, which maps the affinity of each mobile application with the three perspectives on disease. Affinity is a concept drawn from Haraway, who suggests the term affinity instead of identity [24]. Affinity may be helpful for understanding the relation between the disease perspectives and the data set because the technologies should not be categorized based on being identified as representing certain perspectives, but rather by having an affinity with these perspectives. As presented in the previous section, each of the disease-perspectives represents different phenomena and units that are measured and analyzed to establish the disease, illness or sickness. These units 
can be both qualitative (e.g., embodied experiences of pain) and quantitative (e.g., glucose levels or body temperature). Our classification system is based on the understanding that the collection and representations of different types of data in the various functions in mobile technologies support different phenomena; e.g., a sign, such as a fever, can be measured using a thermometer and represented by a number (quantitative), or appear as a symptom, a feeling of being warmer than usual and be represented as a qualitative account of this specific experience. We divided the three perspectives further into subcategories that would aid us in analyzing and structuring the various visions inscribed in mobile health technologies. The subcategories are (i) the type of data; (ii) unit of analysis for the technology; and (iii) means for analysis that best support the applicable perspective. To exemplify, if a mobile application collects numerical values on body temperature and analyzes the data for the user to determine the right course of action, the application is categorized as a disease-affiliated technology in our classification system. Our analysis of mobile health applications was based on a deductive content analysis [36].

Table 1. The proposed classification system for analyzing mobile health applications.

\begin{tabular}{cccc}
\hline Type of Data & Unit of Analysis, Data Units & Means of Analysis \\
\hline $\begin{array}{c}\text { Illness } \\
\text { (subjective) }\end{array}$ & $\begin{array}{c}\text { Primarily qualitative: } \\
\text { symptoms; pain, moods, } \\
\text { emotions, syndromes }\end{array}$ & $\begin{array}{c}\text { Text, audio recordings, video, images, } \\
\text { levels, food intake in } \\
\text { portions/amounts, activity in relation } \\
\text { to context (e.g., place and time) }\end{array}$ & $\begin{array}{c}\text { Self-reflection; relation to } \\
\text { life events, self-initiated } \\
\text { contact with health care } \\
\text { providers; establishment } \\
\text { of own causalities }\end{array}$ \\
\hline $\begin{array}{c}\text { Disease } \\
\text { (scientific) }\end{array}$ & $\begin{array}{c}\text { Primarily quantitative: } \\
\text { numerical values; } \\
\text { signs, markers, }\end{array}$ & $\begin{array}{c}\text { Blood sugar, blood pressure, oxygen } \\
\text { level, temperature, images of } \\
\text { anomalies, quantified occurrence and } \\
\text { severity of symptoms, food intake in } \\
\text { calories, activity in steps, length, } \\
\text { duration, time. }\end{array}$ & $\begin{array}{c}\text { Algorithms, professional } \\
\text { opinion, graphs }\end{array}$ \\
\hline $\begin{array}{c}\text { Sickness } \\
\text { (inter-subjective) }\end{array}$ & Primarily qualitative: & Textual/visual information on course \\
of action & $\begin{array}{c}\text { Comparison to } \\
\text { information, professional } \\
\text { opinion, deviation from } \\
\text { normal behavior. }\end{array}$ \\
\hline
\end{tabular}

It is important to stress that there is space within this classification system for overlapping perspectives within each of the analyzed technologies. One perspective does not exclude another, but it may have a stronger affinity. For instance, although an application might measure markers, such as blood sugar, and analyze this data through the use of an algorithm, the data might still encourage "a relation to life events" and allow for "establishment of patient's own causalities". As such, the classification system provides a first ordering of the data, which will be presented in the following section, followed by a discussion and a second ordering of the affiliations based on the use of health applications by the young patients.

\section{Empirical Data}

The data for our analysis consist of two separate sets. The first set consists of the 18 applications and wearables suggested by the NTC [11]. The NTC's list is continuously updated with new technologies and consisted of 83 "mobile health solutions" at the time of data collection (02.05.2017). In our analysis, we only included the applications and wearables that are available in Norway.

The second set of data consists of six mobile applications, whose use and non-use was reported by 15 young patients aged 13-25 (six male and nine female patients), diagnosed with IBD. They were interviewed as part of a larger project regarding the transition from pediatrics to adult health care services. The participants were interviewed using the Transition Cards method [37], a qualitative card sorting method that we specifically designed to address the various aspects surrounding young patients in transitioning from pediatrics to adult medicine. In addition to asking the participants to sort cards representing important people, things, skills, and feelings into categories representing the various 
stages of transition, we were also interested in their use of digital health technologies. The overall goal was to understand the potential of mobile health technologies in supporting them in the process of transition. The patients were recruited while receiving treatment at two hospitals, the Akershus University Hospital and the Central Hospital in Vestfold. The medical staff decided whether the patients were well enough to participate and introduced them to the study. The patients received an information leaflet and a consent form, which they signed upon meeting the researcher. The research was registered and approved by the ethical board at both hospitals and by the Norwegian Social Science Data Services (NSD). The overall data from the interviews were analyzed using deductive thematic analysis [38], but the mobile health applications that the patients reported on during the interview were analyzed according to the classification system in this article. We have discussed the findings regarding the participant's technology needs and current technology use in a previous article [39].

\section{Visions of Disease}

Our first analysis using our classification system is based on the list of 18 applications and wearables suggested by the NTC and six mobile applications whose use and non-use was reported by the participants in the study on health care transitions (see Tables 2 and 3).

Table 2. Overview of the health applications suggested by NTC. Applications developed with medical practitioners as intended users are marked with *.

\begin{tabular}{|c|c|c|c|c|c|}
\hline$\#$ & Name & $\begin{array}{l}\text { Additional } \\
\text { Device }\end{array}$ & $\begin{array}{c}\text { Unit of Analysis, Data } \\
\text { Units }\end{array}$ & Functionality/Means of Analysis & $\begin{array}{l}\text { Represented } \\
\text { Perspective }\end{array}$ \\
\hline 1 & $\begin{array}{l}\text { Withings Blood } \\
\text { Pressure meter }\end{array}$ & Yes & Blood pressure, pulse & $\begin{array}{l}\text { Overview of the data; Sharing } \\
\text { functionality }\end{array}$ & Disease \\
\hline 2 & $\begin{array}{l}\text { Embrace watch } \\
\text { (epilepsy-wristband) }\end{array}$ & Yes & $\begin{array}{l}\text { Stress levels, sleep, } \\
\text { physical activity }\end{array}$ & $\begin{array}{c}\text { Alerts user and emergency } \\
\text { contacts about occurrence of an } \\
\text { epileptic seizure }\end{array}$ & Disease \\
\hline 3 & iHealth Align & Yes & Blood sugar & $\begin{array}{l}\text { Visualization of data; Sharing } \\
\text { functionality }\end{array}$ & Disease \\
\hline 4 & Digidoc & No & $\begin{array}{c}\text { Oxygen saturation, } \\
\text { heartbeat }\end{array}$ & Visualization of data & Disease \\
\hline 5 & First Derm & No & $\begin{array}{l}\text { Images of skin anomalies; } \\
\text { text-based description }\end{array}$ & Sends images to a dermatologist & Disease \\
\hline 6 & Handyscope * & Yes & Images of skin anomalies & Sends images to a dermatologist & Disease \\
\hline 7 & Skin Vision & No & Images of skin anomalies & $\begin{array}{l}\text { Analysis of image and warns user } \\
\text { via colors where red represents } \\
\text { need for consultation } \\
\text { with specialist }\end{array}$ & Disease \\
\hline 8 & UMSkinCheck & No & $\begin{array}{l}23 \text { images of skin on the } \\
\text { whole body }\end{array}$ & $\begin{array}{l}\text { Analysis over time, notifications, } \\
\text { quiz, information }\end{array}$ & Disease \\
\hline 9 & PoopMD & No & Images of baby's stool & $\begin{array}{l}\text { Analysis of the stool's color, } \\
\text { contact information }\end{array}$ & Disease/Sickness \\
\hline 10 & DermLite & Yes & Images of skin anomalies & Sends images to a dermatologist & Disease \\
\hline 11 & Eko Core * & Yes & Digital stethoscope & $\begin{array}{l}\text { Translation of heartbeat, sharing, } \\
\text { replay, storage }\end{array}$ & Disease \\
\hline 12 & $\begin{array}{l}\text { Dexcom Glucose } \\
\text { Monitoring }\end{array}$ & Yes & Blood sugar & Visualization, sharing & Disease/Illness \\
\hline 13 & HeartAge (Web) & No & $\begin{array}{l}\text { Info: Age, sex, disease } \\
\text { history, cholesterol }\end{array}$ & $\begin{array}{l}\text { Calculates whether user should } \\
\text { seek medical help }\end{array}$ & Disease \\
\hline 14 & MultiBit* & No & $\begin{array}{c}\text { Vision test based on } \\
\text { sharpness of text/images }\end{array}$ & $\begin{array}{l}\text { Automatic sharing with } \\
\text { medical practitioners }\end{array}$ & Disease \\
\hline 15 & EyeHandbook* & No & $\begin{array}{l}\text { Vision test based on } \\
\text { sharpness of text }\end{array}$ & Test, forum & Disease/Sickness \\
\hline 16 & iExaminer * & Yes & Images of user's eye & Sharing & Disease \\
\hline 17 & Fotofinder Hub & Yes & $\begin{array}{l}\text { Images using Handyscope } \\
\text { or DermLite }\end{array}$ & $\begin{array}{l}\text { Cloud-service; evaluation } \\
\text { of results }\end{array}$ & Disease \\
\hline 18 & Eversense & Yes & Blood sugar & Visualization of data; sharing & Disease/Illness \\
\hline
\end{tabular}


We found that 14 of the 18 mobile technologies on the NTC list have an affinity with the disease perspective. Two of the technologies can be placed within the overlap between illness and disease, and two in the overlap between the disease and sickness perspective. The list presented a strong presence of digital health tests and a focus on diagnostics, which supports the NTC's note to the ministry, in which they presents mobile technologies as means to achieve efficiency and cost-reduction in the Norwegian health care system.

Table 3. Overview of the applications that the interviewed patients have used/were using. Applications developed with medical practitioners as intended users are marked with *.

\begin{tabular}{|c|c|c|c|c|c|}
\hline$\#$ & Name & $\begin{array}{l}\text { Additional } \\
\text { Device }\end{array}$ & $\begin{array}{l}\text { Unit of Analysis, Data } \\
\text { Units }\end{array}$ & $\begin{array}{c}\text { Functionality/Means } \\
\text { of Analysis }\end{array}$ & $\begin{array}{l}\text { Represented } \\
\text { Perspective }\end{array}$ \\
\hline 19 & $\begin{array}{l}\text { Luftambulanse } \\
\text { [air ambulance] }\end{array}$ & No & $\begin{array}{l}\text { GPS location, accuracy of } \\
\text { GPS data, time }\end{array}$ & $\begin{array}{c}\text { Contact information, } \\
\text { generation of coordinates }\end{array}$ & Illness \\
\hline 20 & M. Cycles & No & $\begin{array}{l}\text { Cycle duration, symptoms, } \\
\text { temperature, moods, } \\
\text { events, weight }\end{array}$ & $\begin{array}{c}\text { Notifications; Visualization of } \\
\text { data; Calendar; Diary; } \\
\text { Pregnancy mode; } \\
\text { Personalization }\end{array}$ & Illness \\
\hline 21 & IBD appen (IBD app) & No & $\begin{array}{c}\text { Stool consistency, } \\
\text { occurrence, rectal bleeding, } \\
\text { medication } \\
\text { administration, pain }\end{array}$ & $\begin{array}{l}\text { Visualization of data; analysis } \\
\text { and recommendation for } \\
\text { contacting a medical } \\
\text { practitioner; information }\end{array}$ & Disease \\
\hline 22 & $\begin{array}{l}\text { Hodepinedagboka } \\
\text { [Headache diary] }\end{array}$ & No & $\begin{array}{c}\text { Headache } \\
\text { (occurrence, severity) }\end{array}$ & $\begin{array}{c}\text { Visualization of data; } \\
\text { medication administration }\end{array}$ & Disease/Illness \\
\hline 24 & $\begin{array}{l}\text { Applications for booking } \\
\text { appointments with GP }\end{array}$ & No & $\begin{array}{l}\text { Textual description of } \\
\text { patient's condition }\end{array}$ & $\begin{array}{l}\text { Sends information to GP's } \\
\text { office and returns } \\
\text { appointment time }\end{array}$ & Illness \\
\hline
\end{tabular}

Three of the six health-related mobile applications selected and used by the participants (Table 3), have an affinity with the illness perspective. The IBD app was the only disease-specific application within that data set. All interviewees reported on their non-use of this app, even though the IBD app was recommended by their doctors [39]. Two of the apps had a double affinity, disease/sickness, and disease/illness.

Interestingly, none of the 24 technologies could be analyzed as representing only the sickness perspective, which was perhaps due to the focus on self-management both in the list provided by the NTC and in the accounts given by the young patients.

The findings from the analysis of the mobile applications used by the patients indicated that young patients had a different set of "mobile health solutions", which represents contesting visions when compared with the applications presented by the NTC. Our analysis of the data indicated that the patients valued health applications that facilitated them to become the knowers of their bodies and illness. We will discuss this in the following sections.

\subsection{Knowing Devices}

Ten out of the 18 mobile health solutions listed by the NTC required additional measuring devices. Positioned within the disease-vision, they required additional instruments in contrast to the rest of the analyzed technologies, which only used the mobile phone. These additional instruments, such as lenses, blood sugar meters, blood pressure meter, wristband, and stethoscope, could send data to the user's phone. They provide data of higher accuracy and detail by coming closer to the body, enhancing the view of the body, and even getting inside the body through breaching the skin.

The medical practitioners, the receivers of the data sent by several of these applications, were not the only knowers of the body. This is illustrated by the example of the skin anomaly technologies: three out of the six technologies for diagnosing and tracking skin anomalies required additional lenses 
to provide high-detail images of the patient's skin. The technologies mediated an understanding that neither the patient's eyes nor the phone's camera was accurate enough to identify and analyze the skin anomalies correctly. The existence of additional devices might also lead to a situation in which patients view stand-alone mobile applications as limited in their ability to gain knowledge about their skin. The relatively high price of these additional lenses, (around $\$ 1400$ for DermLite), indicate that the average patient will not be able to afford some of these devices. Another three devices (\#3, \#12,\#18) were designed for patients who have diabetes. Here the novelty was the mobile application itself, which accompanied the measuring device and which could visualize the data produced by the device, as opposed to stand-alone glucose measuring devices.

In her comparison between the logic of care and the logic of choice, Mol discussed blood sugar meters [40]. In the logic of choice, the patients become customers and are empowered to choose both their care and the technologies supporting this care. Similarly to other customers, patients are invited to enter the market to buy attractive products, which are marketed in positive terms and "buy as much kindness and attention as they can afford" [40]. The autonomy to choose, whether a patient wants to buy an additional device or not, is presented as a kind of empowerment. On the other hand, this empowerment is undermined when the choice includes expensive products, which are unaffordable to most patients. Since the purchase of expensive medical technologies is the task of the medical institutions, expensive technologies will reinforce the medical gaze, not only in terms of knowing the disease, but also in terms of who controls these instruments of vision.

\subsection{Knowledge Work}

The first ordering in our classification work showed that knowledge of the body and disease required work by the patient. Only two of the technologies in our sample can generate data without manual input or specific measuring actions performed by the users. These two technologies were the NTC-suggested Embrace watch, which is a wristband developed for people who have epilepsy, and the "Luftambulanse" (Air Ambulance) application discussed by one of our participants, which is a mobile application that generates user's GPS location in case of an emergency. All other mobile applications and devices required the user to insert the data through manually: (i) taking pictures of their skin, body, stool; (ii) inserting their symptoms and health data, such as weight, body temperature and also pain and its severity; (iii) puncturing their skin to insert test strips into the blood sugar meters, strapping on the blood pressure meter or placing the stethoscope against their chest; (iv) placing their fingers against the phone's camera and flashlight, and (v) writing down their symptoms. Moreover, several of the mobile technologies suggested by the NTC are dependent on another person assisting the user in producing data, e.g., in the case of UMSkinCheck, which requires someone else to take pictures of the user. Similarly, the functionality of the PoopMD, which is aimed at diagnosing newborns and infants, depends on the parents to take pictures of their child's stool.

The work of the patients and their helper-technologies, such as adjusting their bodies and translating their embodied symptoms into text or numbers, feeds data into the mobile applications for analysis and/or categorization. The majority of the results are visualized in the form of graphs or marked as requiring medical consultation, after algorithmic analysis. In a few of the technologies, however, the patients can share their data with others as well as their physicians.

\subsection{Patient Empowerment}

The majority of the analyzed applications, except for the illness-affiliated ones, view the user as a provider of data about the body to the application, and not necessarily as knowers or decision-makers about their health. It is hard to know if the patients, and not just their bodies, are included in the vision of the technologies, as the data about their bodies are in fact disembodied. The technologies' vision is limited to the input they can process. The results of algorithmic analyses are often perceived as more "factual" and "credible" than the users" embodied and subjective experience and might be rooted in the cultural notion that "seeing" makes knowledge reliable [5]. In other words, algorithmic analyses 
are perceived as "better" knowers of the body than the patients themselves. These cultural beliefs, combined with techno-utopianism, result in a view of algorithms as offering a new form of logic and expertise, described by Lupton and Jutel [7] as "algorithmic authority".

Regardless of the authority of algorithms and patients' pre-diagnostic work, the results of the produced by these mobile health applications are always presented in ways that portray qualified doctors as the final decision makers, advisors, and knowers [7]. Without facilitating a critical understanding of the results and possible methodical flaws of digital health technologies, patients may be left more anxious and with a worsened illness than prior to the information or information visualization provided by the app. Furthermore, diagnoses and results generated by the applications do not offer access to medical treatment nor further laboratory tests or qualify the users for sick leave; the task of diagnosing and granting access to health care resources remains with the medical practitioners [7]. This challenges discourses that link digital health technologies to patient empowerment.

In two of the mobile health applications used by the participants in our study, it was the patient, rather than the algorithm, who had the authority to decide whether the patient should contact a medical professional. Here, the patient can be viewed as the knower of the (her) body and the one who decides whether she would like to seek care and treatment. The role of the health professionals in these two applications is two-fold. In the case of the Air Ambulance app (\#19), the user contacts the emergency department and forwards her coordinates, in order to be transported to the hospital. In the case of the Emergency Medicine Handbook application (\#23), which supports medical personnel to assess the severity and treatment of patients at the emergency ward, the patient assesses if the severity of her symptoms requires a visit to the emergency ward. Such use of the application puts the patient in the position of the knower of her body, while the health care professionals assume the role of resource managers. These two mobile applications represent a traditional approach to health care; only the means of contacting the practitioner have changed.

Apart from the three applications affiliated with the illness perspective (\#19, \#20, \#24), all of the mobile health technologies in the sample relied on medical practitioners, either for diagnosing, treatment or evaluation. Also, six of the applications (\#6, \#11, \#14, \#15, \#16, \#23) were developed for health practitioners; their usage by patients could be compared with patients using analog stethoscopes without any knowledge to support the understanding of the data the technology produces. The analysis according to the classification system demonstrates a strong presence of disease-affiliated technologies on the NTC's list. Combined with the recommendations from the patients' physicians, the support surrounding the disease affiliated applications seems to lack attention to (i) the interests and epistemologies inscribed in mobile health applications (e.g., the "IBD app" was developed by a pharmaceutical company) and to (ii) the unforeseen uses of these technologies.

\section{Appropriating Medical Technology for Patient Empowerment}

The previous section presented a classification based on the functionality and features of the mobile health technologies. The analysis illustrates that the discourses surrounding health technologies that present these technologies as means for achieving patient empowerment, are questionable. Not only did the majority of the analyzed mobile applications lack any information that would educate their users; the patients were not acknowledged as knowers of their diseased bodies. Only the diabetes-management applications could be seen as illness-affiliated insofar that the users were already familiar with blood sugar meters.

In this second ordering of the data, based on how mobile applications are used by the patients in our study, we will continue exploring the question of patient empowerment and who can be a knower. While the first ordering uncovered the affiliations with the disease perspective, we will argue in this second ordering that these affiliations are the effect of visions mediated by technology. Verbeek [41] (p. 99) explains that "technological mediations are not intrinsic qualities of technologies, but are brought about in complex interactions between designer, users, and technologies (... ). [T]echnologies can be used in unforeseen ways, and therefore play unforeseen mediating roles". For example, technologies 
can be used to make disease invisible [42], technologies can be resisted, and technologies can be appropriated in different ways than envisioned by technology designers and health care providers. We will discuss the mediating power of technology in the following examples of the use and non-use of mobile applications.

\subsection{Technologies of Empowerment?}

\subsubsection{Resisting the Algorithm}

The participants in our study, all IBD patients, reported that their clinicians recommended them to use the "IBD app" (\#21), which is an application that processes self-reported data on pain, symptoms, stool consistency, rectal bleeding, and drug administration. Based on the occurrence of the relevant symptoms, the app recommends patient/users to contact their specialist. The participants reported on having downloaded the prescribed application only to delete it after a short period. The young patients found the application's push notifications and reminders to log their symptoms to be annoying and intrusive during symptom-free periods. As explained by one of the participants:

I guess that I forgot it because you are supposed to put in information about how you feel from day to day. And for example, if you have a period when you do not have any illness or symptoms, you will get a reminder a month later. Then it [the IBD app] asks the same questions: "How are you to day" ... so no ... It was too time-consuming. (boy 17a)

Besides, the patients had regular appointments at the clinic. In case their condition worsened, they could contact the clinic or their general practitioner on their own:

It was not something for me, it did not work for me, so I didn't bother to use it [ . . . ]. I don't know... Honestly, I get enough information about [my condition] here [at the clinic]. (boy 17b)

None of the patients were still using the IBD app at the time of the interview.

Within the first ordering in our classification system, the IBD app was categorized as affiliated with the disease perspective. Similar to Ruckenstein [18], we argue on the basis of our findings that applications that do not put the user in the knower-position are of no use to the patients, because, as is applicable to many self-tracking technologies [18], they fail to engage users. However, this interpretation is weakened by one of our participants' account regarding her use of the "Headache diary" (\#22). The "Headache diary" application is aimed at logging the occurrence and severity of headaches and administration of painkillers to correlate her headaches to life events and activities. The patient explained that she did not use the results of the application in her consultations with her doctor, but instead was attempting to relate her headaches to life events and establish her own causalities:

[I use it] only when I have migraine attacks, which is not that often. I am just trying to get an overview and create a picture, if there is any picture to create from using it. (girl 22)

The "Headache diary" became an instrument to extend and structure her own understanding of her diagnosis. She could use her log to understand her headaches and adjust her lifestyle to decrease their occurrence. This case illustrates that although the description of the application clearly states that the results should be discussed with a medical professional, the user can choose to appropriate the purpose of the application to her own needs and knowledge. In this case, the patient can be argued to become empowered as she became more knowledgeable on her illness by connecting the occurrence of her symptoms with certain behaviors and events in her daily life. The patient's unforeseen use (at least to the developers) of the application allowed her to establish her own causalities and become more active in self-care of this specific area of her health.

Lupton [43] argues that the lure of numbers, as indicators of health and representations of the body, is that they appear as scientifically neutral and thus invite people to think of their body through 
numbers [44]. Furthermore, Lupton [43] (p. 399) argues that "it becomes easier to trust the numbers over physical sensations". The findings in our study did not support this argument. However, the creative ways in which the participants negotiated their visions against the functionality and presented results in the mobile health applications raises concerns related to Ruckenstein's [5] argument that the data doubles generated by health technologies "can also profoundly change ways in which people reflect on themselves, others, and their daily lives" (p. 82). When used in unforeseen ways or to serve users' own agendas, especially when the goal is to show adherence to treatment, track the body for the medical practitioner, or to create causalities to change one's behavior, alternative use of mobile health applications might have unexpected and negative health outcomes for people with physical challenges. The inscribed disease vision assumes definitions of disease on the basis of signs and markers $[27,45]$. Consequently, the treatment will necessarily try to change the conditions until the signs and markers are back to "normal". Likewise, a visualization of patients' changing condition in disease-affiliated technologies might lead them to try to change their behavioral patterns to return to "normal". This behavior may be problematic if the technologies alter the patients' understanding of what "normal" is, or the patients alter the representations produced by the technologies until they present their values as "normal".

\subsubsection{Tracking Cycles}

The majority of the applications in our sample have a direct link to a diseased body. They aim to track anomalies, to diagnose, and to facilitate communication with health care practitioners. One of the mobile applications used by the participants in our study cannot be linked to disease as it tracks menstrual cycles, which indicate changes in the state of a healthy body. The inclusion of the "M. Cycles" application and its categorization as affiliated with the illness perspective might be viewed as inappropriate-after all, neither menstruation nor the menstruation cycle is a diagnosis or disease. However, many people with a female reproductive system experience a variety of symptoms and pain in relation to their monthly cycle and while not qualifying as a disease, these symptoms can constitute an illness, especially when combined with other conditions, diseases, or functions in the life of a patient.

Several of the female participants reported on using the "M. Cycles" application. The persistent use of this app contrasts with the reported non-use of the "IBD app", despite both application's focus on tracking of symptoms and patient-reported signs. In addition to tracking the menstrual cycles, "M. Cycles" also allows for input on mood, cycle-related symptoms, weight and body temperature, life events, and sexual and physical activity. In the case of the "M. Cycles" application, push notifications concerning upcoming menstruation and ovulation were welcome by our participants:

I love it [ ... ] It's not certain that I will get it [menstruation] when it says I will, but then I know approximately when I will get it and can be prepared for it. (girl 17)

The functioning of the M. Cycles application does not rely on the input of symptoms or data, other than marking the first day of the user's menstruation. The application's analysis does not propose contacting a physician, and the functionality could be appropriated to life phases during which users will not experience regular menstruations.

Because menstruation cycles are rarely a concern for IBD specialists in their consultations with patients, the benefits of the persistent use of this application befalls only to the users. From a clinical perspective, logging events and tracking of symptoms related to one's menstruation, without the existence of an underlying disease affecting the reproductive system, does not make much sense, but within the patient's illness perspective, this activity might lead to knowledge about the body and aid in coping with the illness and caring for oneself. The reported use of the "M. Cycles" app by the participants indicates the importance of the illness perspective in health technologies. 


\subsubsection{Re-Negotiating the Disease Vision}

The participants reported various apps for booking an appointment with a general practitioner or specialist, and related text-message based appointment reminders, as very useful. Such appointment managing applications build on the illness and sickness perspective and stand in contrast to applications such as the "IBD app" and self-tests in the NTC's list, which delegate the decision of seeing a doctor to algorithms and health professionals. If a person suffers from any symptoms or experiences her patientness, it is her judgment and knowledge of her body that makes her contact a professional for treatment or the legitimization of the symptoms as a disease. The disease-affiliated applications do not assess the qualitative experience of the person's illness before recommending her to contact medical professionals. In this case, it is possible that the applications interfere with the patient's need to contact health care providers, as they mark the symptoms as normal or not severe enough to see a doctor. Applications such as "Air Ambulance" do not make such calculations and facilitate immediate and eased access to help by providing the emergency workers with the patient's position. The participant using the "Air Ambulance" application shared a story of how this application helped her:

It has saved me once, so I am very fond of it. I was hiking in the forest with my boyfriend and felt really sick. We went on a short hike so I did not bring anything with me but we had cell reception and used the app. They came after $20 \mathrm{~min}$. It would have taken longer if it was not for the app [... ]. I think it is great because it gives you safety. (girl 23)

Our assumption about the limits of the disease-affiliated applications is also challenged by the account of one of our participants, who reported on using the "Emergency room handbook" application in deciding whether he should contact the hospital when experiencing symptoms. The handbook had initially been developed to aid emergency health workers in the assessment of patients' symptoms, signs, and markers and provided them with appropriate courses of action. The patient explained that he used the app to locate the combination of symptoms to see if the emergency room staff could do anything or if the combination of symptoms was not severe enough to be prioritized in the waiting line or to receive treatment.

The examples of the reported use of the headache diary and the "Emergency room handbook" illustrate that although mobile health applications can be categorized as affiliated with the disease perspective, they can play unforeseen mediating roles, enabling users to re-negotiated their purpose.

\subsection{Understanding the Different Uses and Appropriations}

From a clinical perspective, tracking signs, markers, and symptoms that do not directly lead to a diagnosis or managing a condition is illogical. Lupton [10] argues that there exists a patronizing "we know better" attitude in representations of the relationship between doctors and patients and their mediating technologies. However, by promoting or even prescribing disease-oriented technologies, such as the "IBD app", the medical practitioners promote ways of knowing and caring for the body which might be oppressive and add additional stressors to the lives of the patients, who already need to juggle the responsibilities and demands of their multiple identities and roles. As Ballegaard et al. [44] (p. 1808) argue, "health and health care technologies are just small pieces that [the patients] try to fit into the larger puzzle of the everyday routines ( ... ). What might make sense from a clinical perspective, might not make sense in the everyday life of a patient". Illness and patient-role are only some of the factors in the participants' lives, while disease, diagnosing, and treatment constitutes the discipline, practice, and professional identity of a medical practitioner. As a result, a tension exists between what the health care institutions, government, and companies perceive as valuable to track, measure, or log and what patients perceive as valuable. Thus, we can understand the use/non-use and appropriation of the mobile health technologies presented in this section as a result of the negotiation between the experience of disease and illness and the different roles and identities of the patients.

It is often taken for granted that mobile health applications are desirable and useful to all, without acknowledging that much of the output of these technologies fail to engage people [18], much like 
in the case of the "IBD app". According to Lupton [10], not all patients wish to be empowered or reflexive. Furthermore, people might not want to engage in self-tracking, because this would make them even more aware of their bodies' limitations or their changing capacities, as one of the most powerful aspects of mobile health technologies is precisely to make visible something that is typically not subject to reflection. In our study, we found that young patients might also not wish to constantly be reminded of their diseases, e.g., during symptom-free periods, or simply refuse to take responsibility for their health. Patients might feel uncomfortable when technologies enter their personal space and may feel invaded or unable to switch off the devices to take time off from tracking their conditions [10]. Uncritical discourses surrounding mobile health applications do not account for how the impact of the longevity of a condition affects the actions undertaken by patient-a person who has never been ill will act differently than someone who has been suffering for years [46]. It is possible that due to the specific time in their life, the participants were entering adulthood, and the chronic nature of their condition, the interviewed patients were resisting the use of apps such as the "IBD app" more than a person who becomes diagnosed with IBD as an adult. However, even if a patient is in fact "hungry for information" about her body, she might lack access to such technologies or the cognitive or physical skills to use them, or find her condition outside of the available functionality of these apps.

As illustrated by the accounts of participants in our study, mobile health technologies are also limited with respect to the aspects of life that are not connected to the illness or disease. As we learned through our work with young patients, patients may also feel the need to experience their quantified life as something more than just the ill body, as showcased by the M. Cycles application. The need for separating the patient's identity from the identity of a "normal" person, is especially evident among adolescent patients [47]. In the case of young patients, contrary to the patients in Pols' [34] study, who were trying to make their condition visible, adolescent patients might want to separate being a patient from being a teenager and make their illness and disease invisible [42].

To fulfill their purpose, health technologies depend on the input of relevant data, as frequently as needed to produce technologically and medically meaningful and accurate analyses and outputs. Thus, from a technological perspective, the "annoying" and intrusive reminders and notifications of the "IBD app", make sense and serve a specific purpose- to track a disease. On the other hand, Lupton [10] questions whether push notifications promote healthy behaviors or rather incite feelings of guilt or shame if the users perceive themselves as lacking self-control and self-discipline. In our case, the push-notifications from the "IBD app" reminded the patients of their diagnosis, even when they felt well and symptom-free. When their symptoms worsened, the patients might understand the visualization of their health status as the result of non-compliance with the prescribed treatment, which can have a major impact on their health and functioning. Moreover, when the condition is chronic or fatal, do patients need to see their disease worsen through quantifiable data? If changes in lifestyle cannot improve their condition, what benefits do they gain by inviting the vision of their practitioners into their private sphere?

\subsection{Self-Tests and Invisible Patients}

When the users notice and quantify every symptom and sign and somehow connect these with their diagnosis, without having this work acknowledged, they might feel neglected and overseen. This may further change the expectations and trust they might have towards health care institutions. As discussed above, not all symptoms and life events are of interest to the medical practitioners because they are not trained to approach health and well-being "in terms of everyday temporalities" [18], and because the vision and epistemology of medical practitioners is not based on holistic and individual observations, but on a multiplicity of similar cases [20]. The medical professionals are reluctant to surrender their authority to patients and people outside of the medical discipline which places the patients and their information in a difficult position [7].

The importance of receiving a diagnosis based on collected data or the embodied experience of an illness is apparent in both popular media and literature within medical philosophy that report 
on patients feeling relieved upon being diagnosed or having the illness legitimized. The available self-tests such as Skin Vision (\#7) or the algorithmic analyses of data offered by the "IBD app" offer a confirmation and a legitimization of one's experiences, but may also lead to what Hung [48] defines as orphaned patients - a situation where there exists a misfit between the formal and medical understandings and experiences of illness. The patients interviewed in our study did not experience becoming orphaned patients both due to their non-use of self- diagnosing tools and due to their long disease history, which taught them to always contact their doctors as soon as they noticed anything unusual about their condition. The patient using the "Headache Diary" used it for her own purposes and did not wish to consult her doctor about the results, which also minimized the chances of feeling neglected and overseen. However, health-seekers and newly diagnosed patients might seek out mobile health applications to translate their illness into disease prior to their consultations and find the efforts to be unacknowledged and not leading to actions in their care, which again contests the proclaimed facilitation of patient empowerment by mobile health applications.

\subsection{Patient Empowerment and the Design of Mobile Health Applications}

Hofmann [4] argues that technology preserves and promotes paternalism and "[m]edical science and technology give the physician an objective account of disease, which makes it legitimate to ignore the perspective of the patient" [4] (p. 683). The large number of disease-affiliated technologies in our first ordering supports Hofmann's argument. However, the unforeseen uses of these applications show that users can become knowers when the mobile applications serve their specific needs or goals. Unfortunately, some of the mediations and appropriations may result in "risky" (according to the medical discourse) self-care practices [49]. Is it possible to include the patients' knowledge and needs and as well as to support the work of the medical practitioners?

Frøisland et al. [50] suggest that it is possible to include the two perspectives productively when designing digital health technology. From a patient perspective, the technology then becomes a means to learn more about an illness and how to communicate and translate it into disease or even sickness, similar to Mol's [19] enactment of the disease perspective taking place in doctor-patient consultations. Frøisland et al. [50] argue that health care personnel "need to recognize patients' existing competencies, experiences, and preferences" to deliver health care that is better tailored to the needs of the public. It is also imperative that, in order to bring the illness perspective into the design of technology, patients become central actors in the design process of mobile health applications and are given opportunities to share their vision in the discourse around digital health technologies [51].

Although the importance of user inclusion in the design of digital health technologies gains increasing support in the design and research community, many technologies continue to be developed with minimal or no patient involvement. Patients "tend to be human factors rather than human actors in the design of digital technology for healthcare" [52] (p. 12), and their involvement is limited to participation in usability testing and as informants. Underestimating patients' ability to contribute to or participate in design results in a lack of patient visions, illness-oriented perspectives, and patients' needs in the final design. If digital health technologies, especially mobile health applications, are to provide direct means to patient empowerment, it is the patients' visions that should be prioritized and inscribed into these technologies.

\section{Concluding Remarks}

This article contributes toward the critical discourse surrounding digital health technologies by providing a classification system to identify various visions of disease inscribed in and mediated by these technologies. The proposed classification system can be helpful in structuring critical analyses of mobile health technologies, which in this study led to questioning of the proclaimed empowerment of patients through such technologies. The data from our interviews with young patients challenged the classification system by showing examples of how users resist and appropriate technologies, often in unforeseen ways that extend the purpose and vision inscribed in these technologies. Haraway [24] 
argues that we become empowered by figuring out, and learning to manipulate, the code that organizes society. In our examples, we illustrate this kind of empowerment by describing how patients appropriate mobile health technologies to fit their life and knowledge. For example, the patient using the "Headache diary" (\#22) chose to apply her own knowledge to the data, instead of following the app's requirements that would allow her doctor to become the knower. Because of the unforeseen and alternative ways in which patients may appropriate mobile health applications, it is important to critically investigate and explore alternative use as well as non-use of health applications and self-tests; to use this knowledge to evaluate the emerging policies; and to design technologies based on the understanding that health application might have a profound impact on how people view and deal with their illness.

We found in our analysis a confirmation of Verbeek's [41] argument that the mediating role of technology implies a "fundamental unpredictability". Through analyzing the visions inscribed and mediated by technologies, and juxtaposing these against the use context and reported use and non-use of mobile health technologies, we demonstrated the importance of critical investigations of technologies. We have used this insight to suggest that it is important, in the pursuit of technology-supported patient empowerment, to include patients' visions in the design of health care technologies and to enable patients to assume the position of expert knowers of their body. This suggestion is grounded in the insight that patients have many roles, contesting identities, and symptom-free periods, in which tracking of a disease might be undesirable and unwelcome. The NTC's understanding of mobile health applications as "solutions" is based on the perception that the diagnoses and treatment of diseases is still the task of medicine. This perspective challenges the patient empowerment discourse woven into the various technological and popular presentations of mobile health applications. The analysis and discussion presented in this paper suggests that empowerment may also mean that patients choose to remove or not to download mobile health applications or that they may alter the application's intended use or they may manipulate the data to present themselves as adhering patients. In the design of mobile health technologies, it is important to remember that they "create opportunities, not obligations" [40]. For health care practitioners, this would imply that they need to open up for the possibility that patients may manipulate their data and establish their own causalities. For the patients, non-use should not lead to a disappearance of patient rights and benefits.

Author Contributions: Margaret Machniak Sommervold analyzed the data and designed the classification system; Maja van der Velden contributed to the discussion; the authors wrote the paper together.

Conflicts of Interest: The authors declare no conflict of interest.

\section{References}

1. Storni, C. The politics of design in Sociotechnical dispositif. Reconciling Healthcare toward a future patient-centric perspective. In Proceedings of the IFIP 2009 Conference on Human Computer Interaction, Berlin, Germany, 24-28 August 2009; pp. 1-19.

2. Lupton, D. The digitally engaged patient: Self-monitoring and self-care in the digital health era. Soc. Theory Health 2013, 11, 256-270. [CrossRef]

3. Lupton, D. Health promotion in the digital era: A critical commentary. Health Promot. Int. 2015, 30, $174-183$. [CrossRef] [PubMed]

4. Hofmann, B. Is there a technological imperative in health care? Int. J. Technol. Assess. Health Care 2002, 18, 675-689. [PubMed]

5. Ruckenstein, M. Visualized and Interacted Life: Personal Analytics and Engagements with Data Doubles. Societies 2014, 4, 68-84. [CrossRef]

6. Klasnja, P.; Pratt, W. Managing Health with Mobile Technology. Interactions 2014, 21, 66-69. [CrossRef]

7. Lupton, D.; Jutel, A. 'It's like having a physician in your pocket!' A critical analysis of self-diagnosis smartphone apps. Soc. Sci. Med. 2015, 133, 128-135. [CrossRef] [PubMed]

8. Sommervold, M.M. "Doctor Smartphone": A Dispositive Analysis of the Norwegian Press's Presentation of M-Health Applications. Int. J. Sociotechnol. Knowl. Dev. 2016, 8, 1-16. [CrossRef] 
9. Lupton, D. Critical perspectives on digital health technologies. Sociol. Compass 2014, 8, 1344-1359. [CrossRef]

10. Lupton, D. M-health and health promotion: The digital cyborg and surveillance society. Soc. Theory Health 2012, 10, 229-244. [CrossRef]

11. Teknologirådet Mobile Helseløsninger. Available online: http://list.ly/list/qOK-mobile-helselosninger (accessed on 5 February 2017).

12. Helse- og Omsorgsdepartamentet Proposisjon til Stortinget (Forslag til Stortingsvedtak). Available online: https://www.regjeringen.no/contentassets/d64fc8298e1e400fb7d33511b34cb382/ no/pdfs/prp201620170001hoddddpdfs.pdf (accessed on 20 February 2017).

13. Ruckenstein, M.; Pantzar, M. Beyond the Quantified Self: Thematic exploration of a dataistic paradigm. New Media Soc. 2015, 19, 401-418. [CrossRef]

14. Lupton, D. You are Your Data: Self-Tracking Practices and Concepts of Data. In Lifelogging: Digital self-Tracking and Lifelogging-Between Disruptive Technology and Cultural Transformation; Selke, S., Ed.; Springer Fachmedien Wiesbaden: Wiesbaden, Germany, 2016; pp. 61-79, ISBN 978-3-658-13137-1.

15. Lupton, D. Understanding the Human Machine [Commentary]. IEEE Technol. Soc. Mag. 2013, 32, $25-30$. [CrossRef]

16. Hofmann, B. The technological invention of disease. Med. Humanit. 2001, 27, 10-19. [CrossRef] [PubMed]

17. Lupton, D. Apps as artefacts: Towards a critical perspective on mobile health and medical apps. Societies 2014, 4, 606-622. [CrossRef]

18. Ruckenstein, M.S. Uncovering everyday rhythms and patterns. Technol. Anthropol. Health Inform. Methodol. Improv. Hum. Technol. Relat. 2015, 215, 28-40.

19. Mol, A. The Body Multiple: Ontology in Medical Practice; Duke University Press: London, UK, 2002; ISBN 0-8223-2917-4.

20. Foucault, M. The Birth of the Clinic: An Archaeology of Medical Perception; Routledge: London, UK, 1973; ISBN 1-135-86483-7.

21. Haraway, D. Situated Knowledges: The Science Question in Feminism and the Privilege of Partial Perspective. Fem. Stud. 1988, 14, 575-599. [CrossRef]

22. Mörtberg, C. Technoscientific challenges in feminism. Nora Nord. J. Fem. Gend. Res. 1999, 7, 47-62. [CrossRef]

23. Haggerty, K.D.; Ericson, R.V. The surveillant assemblage. Br. J. Sociol. 2000, 51, 605-622. [CrossRef] [PubMed]

24. Haraway, D. A Cyborg Manifesto: Science, Technology, and Socialist-Feminism in the Late Twentieth Century. In Simians, Cyborgs and Women: The Reinvention of Nature; Routledge: New York, NY, USA, 1991; pp. 149-181.

25. Verbeek, P.-P. Expanding Mediation Theory. Found. Sci. 2012, 17, 391-395. [CrossRef]

26. Adam, A. Delegating and distributing morality: Can we inscribe privacy protection in a machine? Ethics Inf. Technol. 2005, 7, 233-242. [CrossRef]

27. Hofmann, B. Hva er Sykdom; Gyldendal: Oslo, Norway, 2008; ISBN 82-05-35938-5.

28. Parsons, T. The sick role and the role of the physician reconsidered. Milbank Mem. Fund Q. Health Soc. 1975, 53, 257-278. [CrossRef] [PubMed]

29. Parsons, T. Illness and the role of the physician: A sociological perspective. Am. J. Orthopsychiatr. 1951, 21, 452-460. [CrossRef]

30. Lupton, D. Medicine as Culture: Illness, Disease and the Body; Sage: Newcastle upon Tyne, UK, 2012; ISBN 1-4462-0894-X.

31. Räikkä, J. The social concept of disease. Theor. Med. 1996, 17, 353-361. [CrossRef] [PubMed]

32. Ryff, C.D.; Singer, B.H. Know thyself and become what you are: A eudaimonic approach to psychological well-being. In The Exploration of Happiness; Springer: Dordrecht, The Netherlands, 2013; pp. 97-116.

33. Salloum, I.M.; Cloninger, C.R.; Salvador-Carulla, L.; Otero, A.A. Health Status: From Illness to Wellbeing. In Person Centered Psychiatry; Springer: Berlin/Heidelberg, Germany, 2016; pp. 157-164.

34. Pols, J. Breathtaking practicalities: A politics of embodied patient positions. Scand. J. Disabil. Res. 2011, 13, 189-206. [CrossRef]

35. Bowker, G.; Star, S.L. Sorting Things Out: Classification and Its Consequences; The MIT Press: Cambridge, MA, USA, 1999.

36. Elo, S.; Kyngäs, H. The qualitative content analysis process. J. Adv. Nurs. 2008, 62, 107-115. [CrossRef] [PubMed]

37. Sommervold, M.M.; van der Velden, M. Transition Cards: Design a method with and for young patients. IADIS Int. J. Comput. Sci. Inf. Syst. 2015, 10, 79-94. 
38. Braun, V.; Clarke, V. Using thematic analysis in psychology. Qual. Res. Psychol. 2006, 3, 77-101. [CrossRef]

39. Sommervold, M.M.; van der Velden, M. Technology for Transition: Needs and Preferences of Young Patients. In Proceedings of the eTELEMED 2016: The Eighth International Conference on eHealth, Telemedicine, and Social Medicine (with DIGITAL HEALTHY LIVING 2016/MATH 2016), Venice, Italy, 24-28 April 2016; pp. 257-262.

40. Mol, A. The Logic of Care: Health and the Problem of Patient Choice; Routledge: Oxon, UK, 2008; ISBN 1-134-05317-7.

41. Verbeek, P.-P. Morality in design: Design ethics and the morality of technological artifacts. In Philosophy and Design; Springer: Dordrecht, The Netherlands, 2008; pp. 91-103.

42. Van der Velden, M. In/Visible Bodies: On patients and privacy in a networked world. In Proceedings of the Cultural Attitudes towards Communication and Technology 2012, Murdoch, Australia, 18-20 June 2012; pp. 199-211.

43. Lupton, D. Quantifying the body: Monitoring and measuring health in the age of mHealth technologies. Crit. Public Health 2013, 23, 393-403. [CrossRef]

44. Ballegaard, S.A.; Hansen, T.R.; Kyng, M. Healthcare in everyday life: Designing healthcare services for daily life. In Proceedings of the SIGCHI Conference on Human Factors in Computing Systems, Florence, Italy, 5-10 April 2006; ACM: New York, NY, USA, 2008; pp. 1807-1816.

45. Hofmann, B. The concept of disease-Vague, complex, or just indefinable? Med. Health Care Philos. 2010, 13, 3-10. [CrossRef] [PubMed]

46. Heuwinkel, K. "Nursing ICT" Methodological Approach to Analyse Patients' Needs and Expectations. In Proceedings of the European Conference on eHealth 2006 (ECEH'06), Fribourg, Switzerland, 12-13 October 2006; pp. 239-250.

47. Van der Velden, M.; El Emam, K. "Not all my friends need to know": A qualitative study of teenage patients, privacy, and social media. J. Am. Med. Inform. Assoc. 2013, 20, 16-24. [CrossRef] [PubMed]

48. Hung, Y. Not Yet Cured: Taiwanese Hansen's Disease Patients Living with Sickness after Treatment. Ph.D. Thesis, University of California, Los Angeles, CA, USA, 2013.

49. Iwase, M. The Social Effects of Gestational Diabetes in "High-Risk Ethnic Groups". Ph.D. Thesis, University of Toronto, Toronto, ON, Canada, 2014.

50. Frøisland, D.H.; Årsand, E.; Skårderud, F. Improving Diabetes Care for Young People with Type 1 Diabetes Through Visual Learning on Mobile Phones: Mixed-Methods Study. J. Med. Internet Res. 2012, 14, e111. [CrossRef] [PubMed]

51. Van der Velden, M.; Sommervold, M.M.; Culén, A.; Nakstad, B. Designing Interactive Technologies with Teenagers in a Hospital Setting. In Perspectives on HCI Research with Teenagers; Little, L., Fitton, D., Bell, B.T., Toth, N., Eds.; Human-Computer Interaction Series; Springer International Publishing: Cham, Switzerland, 2016; pp. 103-131, ISBN 978-3-319-33448-6.

52. Kanstrup, A.M.; Bertelsen, P.; Nøhr, C. Patient innovation: An analysis of patients' designs of digital technology support for everyday living with diabetes. Health Inf. Manag. J. 2015, 44, 12-20. [CrossRef]

(C) 2017 by the authors. Licensee MDPI, Basel, Switzerland. This article is an open access article distributed under the terms and conditions of the Creative Commons Attribution (CC BY) license (http:/ / creativecommons.org/licenses/by/4.0/). 